\title{
National Education Policy 2020: Language Perspective
}

\author{
Dr. Jayanta Kar Sharma \\ Founder Registrar, Odisha State Open University, Professor \& Head, Dept. of Hindi, Government Women's College, Sambalpur, \\ Sambalpur-768001, Odisha, India
}

\begin{abstract}
Education is one that can bring national unity in a multilingual nation, as well as it is a good means of maintaining multilingualism and national unity. Linguistic discourse somewhere connects us with our language and speech. Education policy is the basic requirement of any nation, which includes the analysis of the past, the need of the present and the possibilities of the future. Education policy is an important initiative towards ensuring the all-round development of Indian society. It aims to promote the preservation and development of all Indian languages. The main problem in a multilingual and multicultural country like India is to decide which language to use as a medium of instruction. It was for the first time that the mother tongue was made the medium of education at the primary level keeping in mind the interests of the Indian people in education policy. The language issues from paragraphs 4.11 to 4.22 have been presented very carefully under the heading 'Multilingualism and the power of language of this document. The inclusion of vernacular in education will give new life to the endangered languages and will help to keep children connected to their culture. Of course, this will lead to a qualitative increase in the creative ability of the students. India's cultural and social splendour lies in education in the native language i.e. mother tongue. The new education policy lays emphasis on the use of mother tongue or vernacular for the medium of primary education, which aims to advance children in the field of education by keeping children connected to their mother tongue and culture. In order to preserve this multilingual society it is necessary that children have the opportunity to learn multilingual proficiency from school education to college and university education. The National Education Policy 2020 proposes early implementation of a three-language formula to promote multilingualism from the school level. This education policy is a vibrant document to empower the mother tongue and Indian languages. New education policy 2020 has been announced in line with public aspirations and according to national needs and challenges. For the first time in the country, the use of technology in machine learning, artificial intelligence and translation has been emphasised in a policy document. Emphasis has been laid on the study of Indian languages, classical languages, and Sanskrit. The education system has four major dimensions - students, teachers, curriculum and infrastructural facilities. Keeping these four in mind, the new education policy appears with wide potential. If we try to understand in totality, at the policy level, special emphasis has been laid on language-multilingualism, language-education-teaching etc. The new education policy will help in contributing to the development of self-reliant India. If it is implemented well with better coordination with other policies then it will be a far-reaching policy.
\end{abstract}

The objectives of the present study are to find out why and how far the National Education Policy 2020 (NEP2020) was necessary to prepare. How the education policy is an important initiative towards ensuring the all-round development of Indian society. The language issues in the document and how Multilingualism and the power of language of the NEP document can play a vital role for holistic development of the students from primary to higher education.

Keywords - Education Policy; Document; Language; Culture; Mother Tongue; Local Language; Multilingualism; ThreeLanguage Formula.

\section{Introduction}

Education is considered as the fundamental to achieve human potential and develop an equitable society for the national development. The NEP2020 states that universal access to quality education is the key to India's continued ascent and leadership on worldwide in terms of economic process, social justice and equality, scientific expansion, national incorporation, and cultural conservation. The global education development agenda reflected in the Goal 4 (SDG4) of the 2030 Agenda for Sustainable Development, adopted by India in 2015 - seeks to "ensure inclusive and equitable quality education and promote lifelong learning opportunities for all" by 2030."
NEP2020:p.4) Accordingly, on the recommendations of the committee constituted under the leadership of Dr. K. Kasturirangan, the Central Government has presented a roadmap for the transition from primary education to higher education, accepting the 'National Education Policy2020 '. A target has been set to ensure quality education and to promote lifelong education opportunities. National Education Policy-2020 has brought expectations of success with very ambitious and far-reaching results compared to the previous two policies. This is because; the policy has come out after about 5 years of preparations. This is the first national effort after independence, in which Indian languages have been considered in a holistic manner and the power of language has been given importance. The prominence of language in the policy can be understood from the fact that in this 66-page documentthe word of 
'language' has been used 206 times, out of which 126 as plural and 80 times as singular. The 'plural' here signifies that in this document, the emphasis is on plurality cantered on all Indian languages rather than on any one language.If we try to understand in the broader scenario, then we will find that languages play a strong role in connecting our society. Language has special significance in the process of teaching and learning. The current education system promotes the supremacy of English, which hinders the development of the personality of the child and slows down the pace of learning. According to psychology, the child learns easily and quickly in his mother tongue or regional language. The new education policy talks about promoting and preserving linguistic diversity. The education system has four major dimensions - students, teachers, curriculum and infrastructural facilities. Keeping these four in mind, the new education system appears with wide potential. The new education policy lays emphasis on the use of mother tongue or vernacular for the medium of primary education, which aims to advance children in the field of education by keeping them connected to their mother tongue (Home language) and culture.Education requires proper planning and policy. Education is a process of learning that can be achieved through language.

The main problem in a multilingual and multicultural country like India is to decide which language to use as a medium of instruction. Education is one that can bring national unity in a multilingual nation. Linguistic discourse somewhere connects us with our language and speech. In order to preserve this multilingual society it is necessary that children have the opportunity to learn multilingual proficiency from school education to college and university education. Our children are also unable to acquire the basic language skills at school level. A large proportion of school children are lagging in reading, letter knowledge, writing, etc. When these children go to colleges and universities, they do not take interest in language and literature studies.

\section{Literature Survey}

So far as the literature survey is concerned, till now no specific literature is found except the NEP2020 original document published by MHRD, Govt. of India. Furthermore, no specific book or paper is available till now on the particular topic i.e. the language perspective of the NEP2020. This paper will open up various angles to discuss further.

\section{Materials and Methods}

In order to meet the objectives, the paper takes a detail analysis of the National Education Policy 2020 approved by the central cabinet. Out of several issues, the language perspective of the policy has been taken specifically to discuss. Focus has been made on several issues within the issue of language. The NEP2020 original document of erstwhile MHRD department, Government of India is the primary source of the study. The paper may be considered a unique one in terms of language policy of the NEP document and open up many avenues for further discussion on multilingualism, multiculturalism and of course the power of language.

\section{Results}

The aim of this study is how to promote the preservation and development of all Indian languages. It was for the first time that the mother tongue was made the medium of education at the primary level keeping in mind the interests of the Indian people and for holistic development of the personality of Indian students. The objective of including Indian languages in the education system is to save and strengthen them which will give new life to the endangered languages and will help to keep children connected to their art \&culture.

Language as Power: The National Education Policy 2020 presented by the Government of India has brought a ray of hope for all Indian languages. The language issues from paragraphs 4.11 to 4.22 have been presented very carefully under the heading 'Multilingualism and the power of language' of this document. Under this, paragraph 4.11 recognizes that young children learn and understand meaningful concepts in their home language / mother tongue more quickly. So, as far as possible, at least till grade 5 but preferably it is up to grade 8 and beyond, the medium of instruction will be home language / mother tongue / local language / regional language. After this, home / local language will continue to be taught as a language wherever possible. Both government and private schools will comply with this. This is the biggest achievement of the new education policy. This is the condition when the ability of children is highest. During this period, the medium of instruction has been set in the mother tongue i.e. home language or vernacular or regional language, it will have far-reaching consequences and our national spirit will also be strengthened. The very language during which he communicates together with his |along with his"> together with his mother and with his immediate environment also serves to link him with a wider crowd, most of whose members are distant in time and place. Language thus provides a continuity and scope without which a way of overarching nationality couldn't be constructed; it provides concrete, emotionally significant products that the individual received from previous generations and can expire the longer term ones which, within the present, link him to a widely dispersed population, most of whose members he doesn't , and never will, know personally." (Kelman (1971: 54).

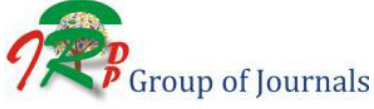


Today, the time it takes to learn English can be appropriated in the expansion of knowledge. Therefore, changing the medium of education in government and private schools in the initial phase will yield very positive results. It has been made clear again in para 4.13 that no language will be imposed on any state. However, the importance of English has also not been denied in this. Higher quality textbooks in all subjects including science will be made available in home languages / mother tongue. Para 4.14 of the format states that all efforts will be made to prepare bilingual textbooks and high quality teaching material in science and mathematics so that students will be able to think and speak on both subjects in both their home language / mother tongue and English. In order to develop linguistic skills in children, especially oral and written communication skills, a year-long fair will be organized in schools in which litterateurs, writers etc. will be invited so that children get an opportunity to interact with them. If these linguistic fairs are held near any good libraries, then children can increase their interest in reading books. Children will also get opportunities to choose their language. Especially after the fifth and eighth grade change their language. Flexibility has been maintained in the choice of language. Dr. Rukmini Banerji, the CEO of Pratham Education Foundation, believes that teachers should able to speak the playground language, which is spoken by students in the playground, to provide effective education in any subject. Speaking to BOOM, Banerji said, "I am from Bihar where nobody speaks Hindi, but rather Bhojpuri or Maithili. In school, if you suddenly face instructions in Hindi, you may not understand. An effort should be made to bring the school closer to the home through the home-language."

There are many levels of languages in the country, including the official language, classical language, eighth schedule languages, etc. But the issue ofendangered language has emerged for the first time in a consolidated policy document, which discusses the 197 languages declared by UNESCO, along with the concern for the preservation and promotion of script less and endangered languages. This linguistic crisis is also seen with tribal languages, it is more or less same with all Indian languages It has eighth schedule languages and classical languages. According to the 1961 census of India, 1652 mother tongues have been reported, including 103 foreign mother tongues. According to the data of the 15 th census 2011, the number of mother tongues recorded by the people is about 19569. After analysing and reviewing the names of these mother tongues, the existence of 1369 rationally rated mother tongues and 1474 unclassified languages has been approved in this report. The total number of languages spoken by more than 10,000 people is 121 . It is impossible to take care of all these mother tongues, but there are currently 22 scheduled languages in priority, but the current education policy has raised hopes, no doubt. On the basis of the census, in the last 30-40 years, the number of speakers of major languages has been decreased gradually, while the population of the country and that region has increased. It is a matter of happiness that this education policy has provisions on the development of teaching and study in all languages including the eighth schedule. It is proposed to update and disseminate them, so that our languages can stand before the English, French, German, Hebrew, Korean and Japanese languages.

Language Teachers: Chapter 22 of this document prescribes that special training is provided to language teachers. It is mentioned in this chapter that language departments will be established in higher education institutions, whose responsibility will be to provide training to language teachers. The trained teachers here will serve in various schools in the country. The professional demand of language teachers is also mentioned in this document. Demand for teachers of Indian languages will increase across the country. This will also provide employment to teachers. Linguistic skills especially oral and written communication skills will be developed in children. According to this document, development and preservation of all Indian languages will be encouraged. Under this, special plans will be made to advance classical Indian languages and literature in higher education institutions. A national institute for Pali, Prakrit and Persian languages will be established. If we try to understand in totality, at the policy level, special emphasis has been laid on multilingualism and language-education-teaching. Apart from this, there are plans to prepare professional teachers and take them forward in their profession, their efficiency, which is linked to continuous professional development program and make them better teachers. At the level of planning, policy etc., this document appears in a positive form.

The language through which the child first communicates with his mother, family and environment, if he gets education for the first few years, his mental development will be better. The following observation by Rutherford is quite significant, There is a minimum of one characteristic that's common to each successful languagelearning experience we've ever known, which is that the learner is exposed a method or another to an adequate amount of the info of the language to be learned" (p.18).

In the era of social media and e-learning, it is not possible for anyone to remain completely untouched by English. Going forward, he can learn it as per his requirement. The responsibility of its system has also been placed in the education policy. English is not a typical foreign language as in case of Spanish, Russian and German languages. The benefit of using home / mother tongue as a medium would be to get rid of the initial hesitation, fear and anxiety.

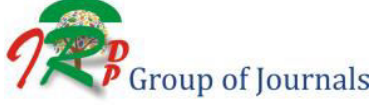


Multilingualism: With the emphasis on multilingualism in the National Education Policy 2020, the changes that are proposed in the schooling system are likely to emerge in the multi-faceted personality of the students. In this context, the document is a systematic and practical effort towards the new construction of modern India and the upgrading of the Indian education system as per the twenty-first century requirement. Early childhood care and education has been included in the education policy keeping in mind the all-round development of children. Along with this, a meaningful initiative has been taken to use mother tongue or regional language for primary and secondary education. Eliminating the imperative of English as a medium of primary level education and widespread use of Indian languages will see far reaching results in basic education. This will pave the way for the advancement of native languages, as well as help in the development of the spirit of Indianness and national unity. Prof. Hans Raj Dua (2008: 44) believes that such thinking and its implementation had two far-reaching effects on Indian society. On the one hand, English got a big boost and thus the economic interests and ideas of the economically influential elite were nurtured, on the other hand, the social status, functions and model for development of local languages suffered a lot. Thus the principles of monolingualism hampered multilingualism and destruction of minority language communities and their linguistic rights, as well as the functions and benefits of linguistic diversity. Education through mother tongue and Indian languages will increase the chances of employability and we will be successful in building a confident future generation. Instead of insisting on securing marks, emphasis has been given on self-reliance and understanding the concept as well as the desire to create a new generation with all-round development in this document. By acquiring knowledge of Indian languages one can actually make the imagination of nation-growth possible by rising above the feelings of caste, religion, regionalism and communalism.

Importance of Mother Tongue: On a practical level, the difference between any two languages is social or political rather than linguistic. In this way, the mother tongue or regional language can express its social values and knowledge in the entire occultation to the new generation through elementary education. Thus, if a language represents a region or a particular society, it will be easy for any child coming from the background of that society to understand the basic education in their language. Govindraj Ethiraj rightly said, "The closer the school language is to the language that the child is familiar with that what is going to build a robust". Many world famous language scientists and academicians like Steven Pinker, Chomsky, Peter Trudgill, etc., have made it clear that the language closest to the maternal language or student's social language is that the most useful language for education . Consistent with sociologist Peter Trudgill, "language as a social phenomenon is closely engaged with the social organization and value systems of society (p. 8)." In this way, if a language represents a region or a particular society, then it will be easy for any child from the background of that society to understand the basic education in their language. But to make these languages educative, there is an urgent need to strengthen them at the structural and conceptual level i.e. without standardization and technical terminology, there will be difficulty in making these languages a medium of instruction and producing text books. Along with this, the new education policy has suggested several measures to improve the quality of teaching along with the educational use of Indian languages. Towards training of continuous professional development for teachers; Use of technology platforms such as SWAYAM / DIKSHA will be available to train teachers through online mode.

Education policy also states that many students come from other states and do not know the regional or local language. In such a situation, its efforts to promote language diversity and multiculturalism can be fruitless. National Education Policy 2020 recommends that students should learn three languages under the formulain their school out of which two languages must be native of India. For example, if a student in Odisha is learning Oriya and English, he has to choose to learn another Indian language. The draft also states that under the three-language formula, it will be mandatory to teach / learn Hindi in states where Hindi is not commonly spoken. After protests from nonHindi speaking states like Tamil Nadu, the central Govt. dropped the reference to compulsory learning of Hindi. The choice of languages will depend on the states and students. However, to be a native of the country, it is compulsory to have at least two of the three languages - one of which is most likely to be a local or regional language. However, a statement issued by the Ministry of Education stated that "no language will be imposed on any student". It is not clear to what extent a student will choose a languagebut the document recognizes India's linguistic diversity, the importance of multilingualism and bilingual education and the need for capacity building in Indian languages.

The use of words like home language, mother tongue and vernacular has been kept so that it can be changed. The three are, in fact, viewed as similar to each other or as alternatives. The language of the home, or what is spoken at a child's home, is transformed into "mother tongue" or "vernacular", as the policy makes no effort to separate them. Is home language always the mother tongue? Will the local language always be the home language? What is the local language of a child? For example, a child from Aligarh who speaks Hindi at home listens to Urdu in the area and learns English at school. What can be the local language of a child whose family speaks Bhojpuri and lives in a Hindi 
speaking part of Mumbai! There is a difference in the local and home language of a North Indian child living in Chennai or vice versa, a South Indian child living in Bihar. Language is a ubiquitous and polymorphic phenomenon, and in India, language boundaries are fluid, as expressed by the term "multilingual". For example, many people who speak Urdu, Hindi and English would describe all three as their language. The question of mother tongue will always be problematic for such individuals and groups. The new education policy promotes multilingual culture and multilingualism is considered as a boon. It is also an opportunity to learn and expand a horizon. However, the complexities of multilingualism also have to be noted.

Translation: The new education policy has brought the concept of the Indian Institute of Translation and Interpretation, under which the work of translating and new interpretation from various fields of knowledge can be done easily. The new education policy also emphasizes that the teaching of all languages will be enriched through innovative and experiential methods and will be taught by combining cultural aspects of languages such as film, theatre, storytelling, poetry and music etc. The use of mother tongue / vernacular as a medium in various higher education institutions and various programs at the level of higher education or running these programs in bilingual form is a major step in this document. This will strengthen Indian languages. Along with this, it has also been said to create degrees and programs related to translation under the higher education system, which is very important in terms of implementation of Indian languages. However, as per the suggestion of the 'National Knowledge Commission', the 'National Translation Mission' has been in operation since 2005 and can be transformed into an institute where there is a comprehensive translation initiative in all Indian languages including English. The tradition of knowledge contained in tribal languages should be placed at the national front.

Classical Language: Looking at the possibility of better teaching and research on the art, history and tradition of the country, Indian classical languages \{Tamil (2004), Sanskrit (2005), Kannada (2008), Telugu (2008), Malayalam (2013), and Oriya ( 2014)\} it has been suggested to connect institutions with various universities. Apart from this, emphasis has also been laid on creating new institutions for Pali, Prakrit and Persian languages. At the same time, it has been proposed to create an independent institute with special emphasis on translation so that the culture of multilingualism and comparative studies of the country can be promoted. With the establishment of National Institutes for Parsian, Pali and Prakrit', it was suggested to strengthen the language department in higher educational institutions and promote mother tongue / local language in form of teaching in higher educational institutions. The new education policy is also involved in setting up academies for all Indian languages included those of Eighth Schedule of the Constitution. Apart from this, it is proposed to collect manuscripts, preserve them, translate and encourage their study. Language, culture and art have been included in this new education policy in such a way that students can develop their own creative, artistic, cultural and academic dimensions. If these language resolutions and provisions are implemented with authenticity in the coming time, then Indian languages will be of great help in containing the symbols and sources of their lost glory. This will emerge an India whose citizens will be blessed with a sense of pride for their language, culture, tradition and heritage, and India will be on the march to a new peak of knowledge. Today there is also a large number of students with disabilities in India. The new education policy for their needs emphasizes on the preparation of teaching materials and infrastructure.

Importance of Sanskrit: Sanskrit has been given special importance in the new Education Policy 2020 of the Government of India. Sanskrit, which some people believe to be dead, still survives in the regional languages of India in the form of Tatsam / Prabhav and Apabhramsa. Sanskrit is a rich language in itself, which needs to be reached to the masses. The important steps taken by the Central Government for the bright future of Sanskrit are commendable. All the Morden Indian languages, some part of Sanskrit is definitely found in them. We use Sanskrit words in different languages. By bringing Sanskrit and other classical languages to the centre, this policy has given a new meaning to the 'Indian Linguistic Area'. Sanskrit will be included in the mainstream curriculum. It will not be confined to single-stream Sanskrit schools and universities, but will be kept in broader perspective. Sanskrit teaching will be made interesting and innovative, and will be linked to other contemporary and relevant subjects such as mathematics, astronomy, philosophy, linguistics, dramaturgy, yoga, and more. According to the document, Sanskrit, while an important modern language mentioned in the Eighth Schedule to the Constitution of India, has a classical literature that is more in volume than Latin and Greek, with vast treasures of mathematics, philosophy, grammar, music.

NEP 2020 in para 4.17 says, "Sanskrit, while also a crucial modern language mentioned within the Eighth Schedule of the Constitution of India, possesses a classical literature that's greater in volume than that of Latin and Greek put together, containing vast treasures of mathematics, grammar, drama, politics, architecture, metallurgy, philosophy poetry, storytelling, medicine, and more (known as 'Sanskrit Knowledge Systems'), written by people of varied religions also as non-religious people, and by people from all walks of life and a good range of socio-economic backgrounds over thousands of years. It'll be taught in ways in which are interesting and experiential 
also as contemporarily relevant, including through the utilization of Sanskrit Knowledge Systems, and especially through phonetics and pronunciation. Foundational and middle school level Sanskrit textbooks may be written in Simple Standard Sanskrit (SSS) to teach Sanskrit through Sanskrit (STS) and make its study truly enjoyable.” (p.14 ).

Other Languages: The classical languages and literature in India like Tamil, Telugu, Kannada, Malayalam, Odia, Pali, Persian and Prakrit will also extensively available as an option for students in schools. Not only languages, dialect is also given importance in this policy. The emphasis is also on making them the medium of teaching. These, classical languages should be modernised as per the need. This may be particularly troublesome where the classical language is associated with religious traditions, as in the Arab world." Fortunately, this is not the case in India. Similar efforts will be made for all Indian languages possessing rich oral and written literature, cultural tradition and knowledge.

Course study materials are developed at the state level and national level for deaf students and Indian Sign Language (ISL) will be standardized across the country. This document on teaching foreign languages states: Apart from high quality teaching material in Indian languages and English, foreign languages like Korean, Japanese, Thai, French, German, Spanish, Portuguese and Russian will also be placed in secondary level. In order to know the cultures of the universe and broaden their knowledge horizon, students should study important foreign languages. As regard to Chinese, this language has been dropped due to the recent Indo-Chinese conflict.

Endangered Languages: Languages are repositories of historical/geographical knowledge and healthy community interactions. Indigenous people speak hundreds of languages."(Vijay Tyagi)It is known that without the use of language, one often dies. In fact, this is the first policy document of the Government of India in which the issue of distressed languages has been raised so seriously. In this policy, there is a clear mention that the government is not only worried about the extinct languages, as well as it is sensitive to those languages which cannot be categorized as endangered languages but they also have no fewer problems. The importance of languages connecting language with art and culture is discussed in para 22.4 of National Education 2020. At the same time, emphasizing on preserving and promoting the languages of culture for conservation, promotion and propagation of culture is a commendable step. Para 22.5 expresses the concern over the extinction of languages in India. It states that "Unfortunately, Indian languages have not received proper attention and care under which the country has lost 220 languages in the last 50 years." UNESCO has declared 197 Indian languages as 'Endangered'."(NEP2020) “Around
100 of these 197 endangered languages are from tribal areas of the North-eastern region of India (NEI).

When a senior member of a community or tribe speaking that language dies, often that language also ends with them; and often no concrete action or measures are taken to preserve or record the expressions of these rich languages / culture. Moreover, various problems pertaining to 22 scheduled languages of the Constitution of India are also discussed in Para 22.6 of this document. Learning materials and dictionaries in these languages will also have to focus on preparation and continuous promotion.

Indian Languages: The new education policy has also included the importance of Hindi language by adjusting the influence of mother tongue primarily. Along with Hindi, the importance of Indian languages should also be made and the dominance of English should be eliminated. The mother tongue has unmatched importance in it. The new education policy, along with being based on Indian values of life, emphasizes on the promotion, restoration and propagation of Indian traditions, Indian culture and Indian languages, making it an important role in making India a capable, glorious, self-reliant. All the rich language thinkers have believed that for the prosperity of the country it is necessary to create an environment of the native language in which high quality education should be equally available in the languages. A strong democratic India can be built on this basis. Overall, we can say it as an Indiacentric education policy.

Language and Culture: The language and culture are both sides of the same coin. When language comes, it brings with it its culture and when it goes, it also takes its culture along. According to Indian culture, the need for a new education policy was being felt for a long time and it was also felt that Indian languages along with Hindi should be given importance in this education. Hindi is the language of nationality, making it the official language and enshrining it as a symbol of nationality should be the priority of the new education policy. The main objective of the new education policy is to make people aware that they cannot develop till they fully use all Indian languages including Hindi, and will not get national pride. The basis of Indian nationality is its composite culture, which has continuity with the languages of India. Therefore, compulsory teaching of the languages of the Union and the States is also necessary from the point of view of unity integrity of the country. All the thinkers and academicians of the country and the world believe that education in mother tongue is the best for the development of the individual. In almost all developed countries, the medium of instruction is their own languages and on the contrary most countries with foreign language medium are underdeveloped or under development category. The secret of the development, self-respect and self-confidence of the

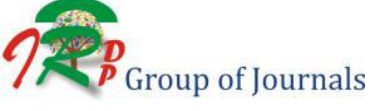


people of European, American, Germany, Japan, Russian, Korean etc. is to give love, respect and top priority to selflanguage. They stand alive with pride and pride with their language \&culture with all science-technology and economics. This is not happening to us, because we did not understand the importance of national identity, selflanguage and self-culture. While this is what makes us our independent identity, and increases the pride of the nation. Western culture is served through English language teaching at all levels from nursery poems, stories and other texts in India's seasons, rivers, mountains, dance, music, festivals, traditions, history, mythological stories, saints and the people belong to western countries. There is not even a glimpse of Indian culture in the text. Due to this, from the childhood, the students start leaning towards western culture instead of Indian culture and they start to accept western culture better than Indian culture. Hindi is a symbol of nationality and nation because Hindi is the language that connects India in socio-political-geographical and linguistic terms. Even if Hindi is the official language of the nation, it has not been given importance in the policy document in order to democratise the language policy.

Three-language Formula: The New Education Policy 2020 proposes early implementation of a three-language formula to promote multilingualism from the school level. The document states that the three-language formula will be applied to the need to promote constitutional provisions, people, territories and union aspirations, and promote multilingualism as well as national unity. "The threelanguage policy emphasizes the utilization of a national language as a teaching medium up to Class 5 of the kids.

Students in class and better education will have the choice of Sanskrit and other ancient Indian languages, but no student will have any obligation to settle on the language. The policy calls to provide the option of three languages and out of which two will be indigenous languages for the students (Sonali Sinha). However, the document also states that the three-language formula will be more flexibility, and no language will be imposed on any state. The children will learn the states, regions, and of course the students' choice, so long as at least two of the three languages are from India. "The NEP 2020 brings with a novel idea of implementing three-language formula with the view to encourage multilingualism and national unity. The new education policy gives the right to the states to decide the language of their choice. The NEP 2020 provides fluidity to the three-language formula as there is no specific language that shall be imposed on any state."In particular, students who wish to change three or more of the languages they are studying may do so in grades 6 or 7 , as long as they are able to demonstrate basic proficiency in the three languages. There will be a major effort from both the Central and State Governments to recruit a large number of language teachers in all the regional languages across the country, and in particular, all the languages mentioned in the $8^{\text {th }}$ schedule of the constitution. The teaching of the child in the mother tongue under the trilingual formula was also stated in the Kothari Commission's 1986 education policy, but that recommendation could not be implemented in its entirety in the country. There was a provision of teaching a regional, a national and a foreign language in schools under the Three-language formula. Significantly, after the implementation of the formula, there was a voice of opposition especially from the southern states. Under it, English and Hindi, a regional language, were kept in schools. After the protest it was made flexible and no language was made compulsory. Under this, the implementation of the trilingual formula in the Hindi speaking states was ignored. Hindi and English remained, but no measures were taken to teach any other Indian language. No Hindi speaking state has included any South Indian language in the curriculum of its schools. In the context of trilingual formula, there is nothing new in the new education policy this time, but there is newness in its presentation. The new education policy-2020 aims to develop India into a knowledge-based society. In other Hindi speaking states it will be other modern Indian language or English. In case of non-Hindi areas, it can be Hindi or English. The third language will be English or a modern Indian language in the Hindi speaking states. In a non-Hindi speaking state, it will be English or one of the modern Indian languages. According to the committee's report, language learning is an important part of a child's cognitive development. Its aim is to promote multilingualism among students. States like Tamil Nadu, Puduchery and Tripura have objected to the adoption of Hindi under the trilingual formula in their schools. Not only this, often state governments also do not have enough resources to implement the three-tier linguistic formula. Special attention is needed for these issues. "The policy appears good but, there are riders. The cognitive burden is higher for these kids," - Ganesh Devy, the man worked behind the People's Linguistic Survey of India.

The languages of India, along with their art and culture, will be documented through online portals, web and wiki to preserve the original language and their knowledge. The general public will also be invited to contribute to the portal and add their learning resources, with high-level knowledge of the language. These web portals will be managed by universities and their research team and funded by NRF. Students will be awarded scholarships on the basis of language. Various awards and incentives will be awarded for outstanding poetry and prose in Indian languages in the context of various categories, which will be established to ensure vibrant novels, poetry, journalism, textbooks and other works. In addition, proficiency in a language at the time of employment will also be considered a key quality parameter. It is also important to emphasize 
the delivery of education in different languages which will help to make students adaptable to multilingual education. In addition, language education should be improved not only in terms of literature, grammar and language vocabulary, but also to interact with students in the same language. Teachers with high-level knowledge of a particular language will be appointed to impart education to students for the respective language. There will be a four-year B.Ed. degree which will focus primarily on increasing knowledge about native languages, through which teachers will be appointed as language expertise.

Language Diversity: Linguistic discourse somewhere connects us with our language and speech and also makes us part of a multi-lingual society where languages are heard, spoken and read in a very little distance. There is no doubt that the expressive capacity of a person living in a multilingual society can be seen and heard in every sphere of his life. In order to preserve this multilingual society it is necessary that children have the opportunity to learn multilingual proficiency from school education to college and university education. "The true relation between language development and diversity has evident and possible suggestions for the developmental linguistic planning. if there is no relation between development and language diversity, then goals in each domain can be pursued independently.

However, language teaching is one side of this policy. Apart from this, there are plans to prepare professional teachers and take them forward in their profession, their efficiency, professional development which is linked to continuous professional development program and make them better teachers. This document appears complete at the level of planning, policy etc. but in the other hand we see large number vacancies of teachers in schools to colleges, universities, in such a situation, Govt. should be serious about separate appointment of language teachers. Achieving the appointment target is an important issue.

India is a multilingual country and judging from this multilingualism is a major objective of this national policy. Now we have to see how it is implemented, because some of these policies like emphasizing the mother tongue, the trilingual formulas, etc. were already there in the earlier policy under Kothari Commission report, but there has been no concerted effort to comply with them. Presently, the attention of scholars was particularly attracted towards languages when they realized that many languages of the world are not being learned by the new generation. Are adopting technically strong and prestigious languages? The influential linguistic communities played the biggest role because they gradually began to deny their existence by considering their languages as a frivolous dialect. The establishment of English at the center of the education system created a rift between the English and Indian languages in Indian society and this led to social and economic inequalities which led to the fury of the concept of a just society. If education is available in Indian languages, then the children of millions of farmers will be benefited.

\section{Conclusion}

Language is a vital part of our education system in our country which plays an important role in strengthening the societal fabric in general and imparting education to the children in particular. But due to the existing federal structure and diversity in language, no local or regional languages have given importance or supremacy over other languages in India. The three-language formula in the policy document wills certainlygive a boost toour education system and removes social disparity. Most of the reforms in the NEP 2020 are very appreciative. Things should be changed with the need of the time which should be for the welfare of the society. Education is the key to human life and social change. The changes in education should be good for development of a society; hence the NEP 2020 with its new vision will definitely bring good changes in our education system. Education policy is an important initiative towards ensuring the all-round development of Indian society. It aims to promote the preservation and development of all Indian languages. It was for the first time that the mother tongue was made the medium of education at the primary level keeping in mind the interests of the Indian people in education policy. Also, one of the objectives of including Indian languages in the education system is to save and strengthen them. The inclusion of vernacular in education will give new life to the endangered languages and will help to keep children connected to their culture. Of course, this will lead to a qualitative increase in the creative ability of the students. It is important to establish India's cultural and social splendour in the minds of young generation which lies in education through the native language i.e. mother tongue. All behaviour without knowledge and study of mother tongue is considered meaningless. Education policy is the basic requirement of any nation, which includes the analysis of the past, the need of the present and the possibilities of the future. Ironically from the point of view of education policy, education was left neglected by the governments after the first in 1968 and second education policy in 1986. Importance has been given to all Indian languages including Hindi. Majority and democracy have been respected in this document. Education, research and innovation are important in this era of knowledge, while respecting the spirit of Ek Bharat Shreshtha Bharat. For the first time in the history of India, the views of about 2.5 lakh Grampanchayats, 6600 blocks and 650 districts were taken for framing the education policy. After taking suggestions from academics, teachers, parents, public 
representatives and students at a wider level, the committee brainstormed in many sessions and prepared the document. This policy is a vibrant document to empower the mother tongue and Indian languages. New education policy 2020 has been announced in line with public aspirations and according to national needs and challenges. For the first time in the country, the use of technology in machine learning, artificial intelligence and translation has been included in a policy document. Emphasis has been laid on the study of Indian languages, classical languages, and Sanskrit. The teaching scriptures of school education will be translated. Enriching the corpus vocabulary in the Indian language, spreading propaganda, reaching the people, modernizing, establishing translation and interpretation institutions, all these have been taken care of. If it is implemented well with better coordination with other policies then it will be a far-reaching one. Rabindranath Tagore in his poem 'Bharat Teertha' wrote, "No one knows at whose beckoning call how many streams, of humanity came in indomitable waves from all over the world, over the millennia and mingled like rivers, into this vast ocean and created an individual soul, that is called Bharat". Hope, the National Education Policy 2020 through its diverse language perspective will achieve that milestone what Gurudev Rabindranath imagined in the great poem BharataTeertha.

\section{Acknowledgements}

This paper was originally presented in Hindi language in an International Conference organised by Vasant Mahila Mahavidyalay, Rajghat, Baranasi under BHU in presence Shri Kalraj Mishra, His Excellency, Honourable Governor of Rajasthan in the first session. I acknowledge NEP 2020 document of MHRD, Govt.of India (both English \& Hindi edition) which is the primary source in preparing this paper.

\section{References}

[1] Dua, Hans Raj. "Ecology of Multilingualism". Mysore: Yashoda Publication.2008

[2] Fishman, Joshua A. "National Languages and Languages of Wider Communication in the Developing Nations". Paper presented at the Regional Conference on Language and Linguistics, Dar es Salaam, Tanzania.1968
[3] Kelman, Herbert C,"Language as aid and barrier to involvement in the national system." In Joan Rubin \& B. Jernudd (Eds.) Can language be planned? Sociolinguistic theory and practice for developing nations. (pp. 21-50). Honolulu: University of Hawaii Press.May,2019

[4] "Language as aid and barrier to involvement in the national system." In Joan Rubin \& B. Jernudd (Eds.) Can language be planned? Sociolinguistic theory and practice for developing nations. (pp. 2150). Honolulu: University of Hawaii Press, May, 2019

[5] MHRD "National Education Policy 2020", Ministry Of Human Resource Development, Government Of India, New Delhi.2020

[6] Pool, J. "National development and linguistic diversity". In J.A. Fishman (Ed.), Advances in the sociology of language. (Vol. 2, pp 213-230), The Hague: Mouton.1972.

[7] Rutherford, William E. "Second Language Grammar: Learning and Teaching." London; New York: Longman. 1987

[8] Trudgill, P. "Sociolinguistics: An introduction to language and society." Fourth edition Penguin, UK,2000.

[9] GovindrajEthiraj(August 5, 2020) "National Education Policy 2020: Instruction Should Be In The Language Of The Playground" https://www.indiaspend.com/national-education-policy-2020instruction-should-be-in-the-language-of-the-playground/ retrieved on 30.11.2020

[10] Devy, Ganesh. https://www.nationalheraldindia.com/india/modigovts-new-education-policy-is-nothing-but-a-national-exclusionpolicy-say-experts/retrieved on 30.11.2020

[11] Three language formula: History and Analysis, Retrieved from https:// iasbaba.com / 2020/08 / three-language-formula-history-andanalysis/ retrieved on 30.11 .2020

[12] What is the three-language formula, (August 16, 2020), Retrieved from http://lawtimesjournal.in/what-is-3-language-formula/

[13] Banerjee, Rukmini (Dr.). https://www.boomlive.in/fact-file/nep2020- home- language- vs- english-and- the- new- three- languageformula- 9141/ retrieved on 30.11.2020

[14] https :// www. indiatoday.in / education-today / news / story / nep2020- makes- studies- compulsory- in-regional-language-upto-class5-school-principals-t hink- english-is-important- 1706442-2020- 07$31 /$ retrieved on 30.11 .2020

[15] Sinha. Sonali, "The Three Language Formula Under The National Education Policy, 2020" https://www.lawyered.in/legal-disrupt/ articles / three- language- policy- under- national- education- policy$2020 /$ retrieved on 30.11.2020

[16] Tyagi,Vijay.(August 17, 2020)“The New Education Policy 2020: Addressing language deprivation and economic survival of tribal mother tongue speakers" https://thedailyguardian.com/the-neweducation- policy- 2020- addressing- language- deprivation- andeconomic- survival- of- tribal- mother- tongue-speakers / retrieved on 30.11 .2020 